\title{
Analysis of Double U-slot Cut Rectangular Microstrip Antenna
}

\author{
Amit A. \\ Deshmukh \\ EXTC, DJSCOE \\ Vile - Parle (W), \\ Mumbai, India
}

\author{
Rishi Ahuja \\ EXTC, DJSCOE \\ Vile - Parle (W), \\ Mumbai, India
}

\author{
Monal Mehta \\ EXTC, DJSCOE \\ Vile - Parle (W), \\ Mumbai, India
}

\author{
Shafin \\ Nagarbowdi \\ EXTC, DJSCOE \\ Vile - Parle (W), \\ Mumbai, India
}

\begin{abstract}
The analysis of dual band double U-slot cut rectangular microstrip antenna is presented. The reported double U-slot cut rectangular microstrip antenna yields dual and wide band operation in 2100 and $5400 \mathrm{MHz}$ frequency bands. To analyze the dual band response at above frequencies, the resonance curve plots and surface current distributions for equivalent rectangular patch and single U-slot and further double U-slot cut rectangular microstrip antennas were studied. The first $\mathrm{U}$ slot primarily optimizes the position of $\mathrm{TM}_{01}$ and $\mathrm{TM}_{20}$ modes of the patch to realize dual and wide frequency response in $2100 \mathrm{MHz}$ frequency range. Further the second U-slot optimizes the position and impedance at higher order modified modes like $\mathrm{TM}_{22}, \mathrm{TM}_{31}$ and $\mathrm{TM}_{02}$ modes to yields dual frequency response in $5400 \mathrm{MHz}$ frequency band. Since the higher order modes are involved in dual band response, the cross polar levels in higher frequency band are higher as compared to first frequency band. The present study gives an insight into the functioning of U-slot cut patches at their lower as well as higher order frequency bands.
\end{abstract}

\section{Keywords}

Rectangular microstrip antenna, Dual band microstrip antenna, U-slot, Higher order mode

\section{INTRODUCTION}

More commonly used technique to realize dual band microstrip antenna (MSA) is by cutting the slot at an appropriate position inside the patch $[1-5]$. The slot is said to introduce a mode near the fundamental patch mode when its length either equals half wave or quarter wave in length to yield dual frequencies. A single polarization is realized when the radiated fields due to slot mode and patch mode, are in same direction, whereas when they are orthogonal, it yields dual polarization. These dual band slot cut MSAs are mainly reported at the fundamental patch mode. Recently by cutting two concentric U-slots inside rectangular MSA (RMSA), a dual and wide band response in two different frequency bands is reported [6]. The reported double U-slot cut RMSA covers AWS, GSM, WiMAX and WLAN frequency bands (1710 $1755 \mathrm{MHz}, 1805-1880 \mathrm{MHz}, 1900-1990 \mathrm{MHz}, 2.110-$ $2170 \mathrm{MHz}, 2400-2500 \mathrm{MHz}, 5150-5350 \mathrm{MHz}$, and $5450-$ $5850 \mathrm{MHz}$ ) [6]. To cover these various frequency bands, dual and wide band operation is needed in $1700-2500 \mathrm{MHz}(\mathrm{BW}$ $\sim 38 \%)$ and $5150-5850 \mathrm{MHz}(\mathrm{BW} \sim 14.5 \%)$ [6]. In the reported literature for dual and wide band antennas, planar monopole antenna, have been used [7 - 10]. However they give bi-directional radiation pattern which will find them unsuitable for deploying them on the panel of an aircraft, since more and more efforts are put in by aviation industry to provide wireless connectivity in the flight. The back-radiation from the aircraft panel can change the antenna characteristics.
Therefore in those applications double U-slot cut RMSA was used which gave wide band response at 2100 and $5400 \mathrm{MHz}$, with radiation pattern in the bore-sight direction. The most of reported slot cut broadband and dual band MSAs are designed using half wave or quarter wavelength approximation for the slot length. The recent study on slot cut MSA showed that slot does not introduce any additional mode but reduces the resonance frequency of higher order patch mode and along with its fundamental mode, yields dual band or broadband response [11]. The above analysis was carried out for single slot cut MSAs around the fundamental patch mode wherein maximum two resonant modes are present.

In this paper, an analysis of above reported multi-resonant double U-slot cut RMSA is presented. First the reported configuration was simulated using IE3D software [12]. In IE3D simulations, 15 cells per wavelength were taken, which reduces computation time and gives fairly close matching with reported result. The resonance curve plots and surface current distributions for RMSA, U-slot cut RMSA and double U-slot cut RMSA for varying slot lengths were studied. The first U-slot reduces and optimizes the position of $\mathrm{TM}_{01}$ and $\mathrm{TM}_{20}$ mode frequencies of equivalent RMSA to realize wide band response around $2100 \mathrm{MHz}$. This U-slot also reduces other higher order mode resonance frequencies like, $\mathrm{TM}_{21}$, $\mathrm{TM}_{22}, \mathrm{TM}_{02}, \mathrm{TM}_{31}$ and $\mathrm{TM}_{30}$. The second concentric U-slot further optimizes the frequencies and input impedance at above higher order modes and yields dual frequencies around $5400 \mathrm{MHz}$ frequency band. In the lower frequency spectrum, maximum of surface current components are aligned along vertical direction inside the patch, which leads to broadside radiation pattern with lower cross polarization levels. In higher frequency band, the surface currents are directed along patch length as well as width which lead to radiation pattern with higher cross polarization levels. The proposed analysis gives an insight into the functioning of multi-resonant double U-slot cut antennas at lower order as well as various higher order modes.

\section{DOUBLE U-SLOT CUT RMSA}

The double U-slot cut RMSA is shown in Fig. 1(a, b) [6]. The antenna consists of three layer dielectric substrate. The outer layers are of dielectric constant 3.5 with thickness of $0.06 \mathrm{~cm}$. The sandwich layer has dielectric constant of 1.05 with thickness of $0.805 \mathrm{~cm}$. The simulated and measured return loss $\left(S_{11}\right)$ plots are shown in Fig. 1(c). It shows dual and wide band response at frequency of around $1700-2500 \mathrm{MHz}$ and $5150-5185 \mathrm{MHz}$. To understand dual wide band response, double U-slot cut RMSA is simulated using IE3D software and its resonance curve and return loss $\left(S_{11}\right)$ plots are shown in Figs. 1(d) and 2(a), respectively. The $S_{11}$ plot shows close resemblance with the reported results. The resonance curve shows five peaks and surface current distribution at them are 
shown in Fig. 2(b-e) and 3. At first two frequencies surface currents are varying along vertical direction whereas at remaining three frequencies they are varying along patch length and width. To understand the dual wide band response its analysis is carried out as discussed in following section.

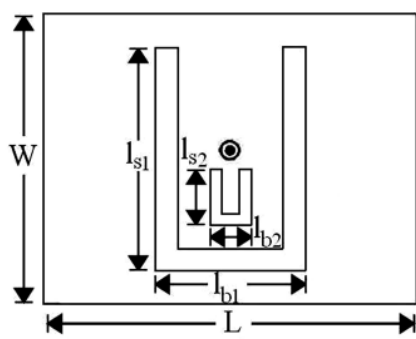

(a)

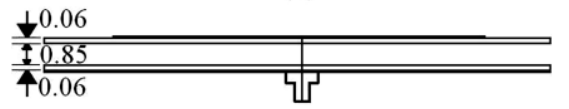

(b)

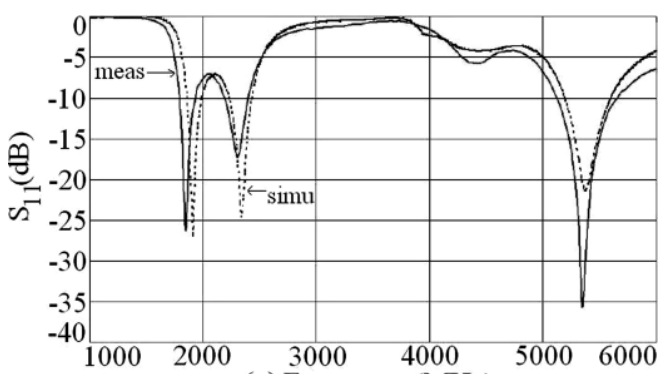

(c) Frequency $(\mathrm{MHz})$

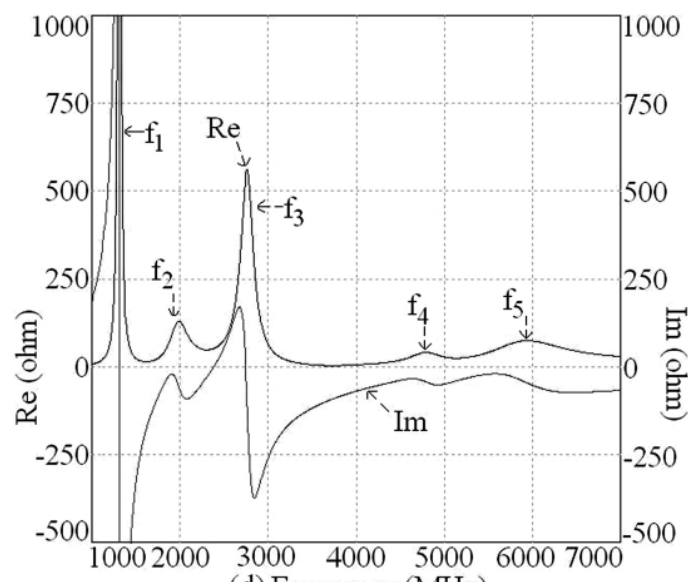

(d) Frequency $(\mathrm{MHz})$

Fig. 1 (a) Top and (b) side views of double U-slot cut RMSA and its (c) return loss [6] and (d) resonance curve plots

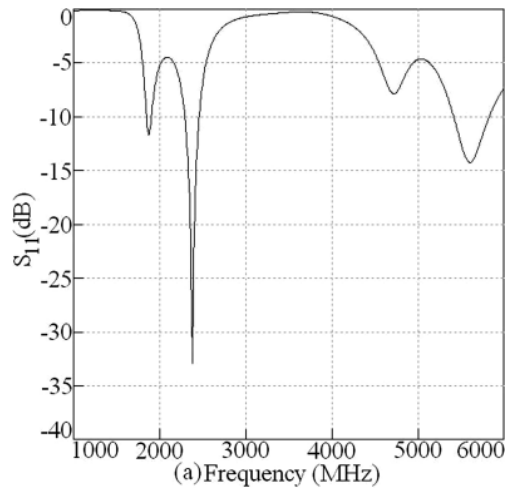

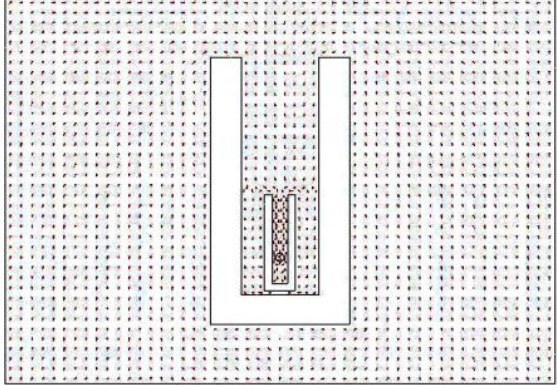

(b) $\mathrm{f}_{1}=1308 \mathrm{MHz}$

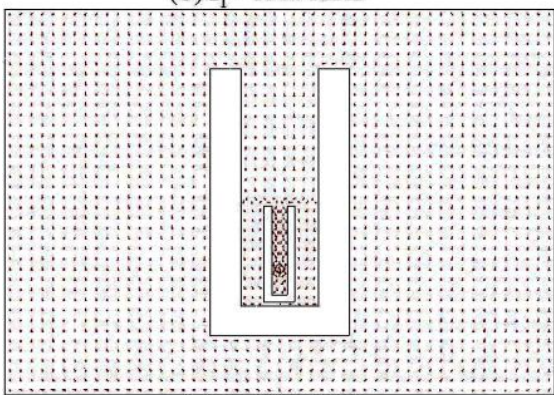

(c) $\mathrm{f}_{2}=1979 \mathrm{MHz}$

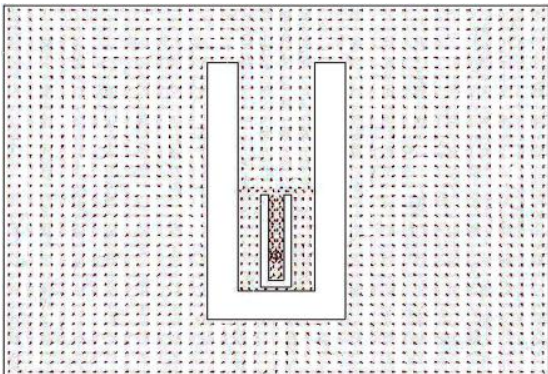

(d) $\mathrm{f}_{3}=2764 \mathrm{MHz}$

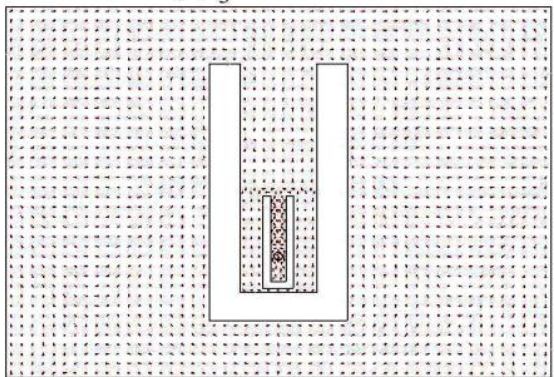

(e) $\mathrm{f}_{4}=4788 \mathrm{MHz}$

Fig. 2 (a) Return loss plot and (b-e) surface current distribution at various peaks for double U-slot cut RMSA

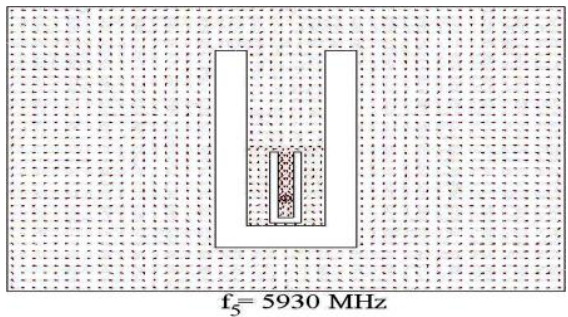

Fig. 3 Surface current distribution at last peak for double U-slot cut RMSA 


\section{ANALYSIS OF DOUBLE U-SLOT CUT RMSA}

The equivalent RMSA dimensions in double U-slot cut configuration are, $\mathrm{L}=7.1 \mathrm{~cm}$ and $\mathrm{W}=5.2 \mathrm{~cm}$. The patch is fabricated on three layer dielectric substrates. The effective dielectric constant for the same is calculated by using following equation.

$\varepsilon_{\mathrm{re}}=\frac{\left(\mathrm{h}_{1}+\mathrm{h}_{2}+\mathrm{h}_{3}\right) \varepsilon_{1} \varepsilon_{2} \varepsilon_{3}}{\mathrm{~d}_{1} \varepsilon_{2} \varepsilon_{3}+\mathrm{d}_{2} \varepsilon_{1} \varepsilon_{3}+\mathrm{d}_{3} \varepsilon_{1} \varepsilon_{2}}$

$\mathrm{f}_{\mathrm{TMmn}}=\frac{\mathrm{c}}{2 \sqrt{\varepsilon_{\mathrm{re}}}} \sqrt{\left(\frac{\mathrm{m}}{\mathrm{L}_{\mathrm{e}}}\right)^{2}+\left(\frac{\mathrm{n}}{\mathrm{W}_{\mathrm{e}}}\right)^{2}}$

Where, $\varepsilon_{\mathrm{re}}=$ effective dielectric constant,

$$
\begin{aligned}
& \varepsilon_{1} \text { and } \varepsilon_{3}=3.5, \varepsilon_{2}=1.08, \\
& \mathrm{~h}_{1} \text { and } \mathrm{h}_{3}=0.06 \mathrm{~cm}, \mathrm{~h}_{2}=0.85 \mathrm{~cm} \\
& \mathrm{c}=3 \times 10^{8}(\mathrm{~m} / \mathrm{s}), \text { velocity of light } \\
& \mathrm{L}_{\mathrm{e}}=\text { effective patch length } \\
& \mathrm{W}_{\mathrm{e}}=\text { effective patch width }
\end{aligned}
$$

By using equation (1), effective dielectric constant is calculated and by using equation (2), various resonance frequencies of RMSA, in 1000 to $7000 \mathrm{MHz}$ frequency band are calculated and they are, $\mathrm{f}_{\mathrm{TM} 10}=1626 \mathrm{MHz}, \mathrm{f}_{\mathrm{TM} 01}=1929$ $\mathrm{MHz}, \mathrm{f}_{\mathrm{TM} 11}=2523 \mathrm{MHz}, \mathrm{f}_{\mathrm{TM} 20}=3251 \mathrm{MHz}, \mathrm{f}_{\mathrm{TM} 21}=3781$ $\mathrm{MHz}, \mathrm{f}_{\mathrm{TM} 12}=4186 \mathrm{MHz}, \mathrm{f}_{\mathrm{TM} 02}=3858 \mathrm{MHz}, \mathrm{f}_{\mathrm{TM} 22}=5045$ $\mathrm{MHz}, \mathrm{f}_{\mathrm{TM} 30}=4877 \mathrm{MHz}, \mathrm{f}_{\mathrm{TM} 03}=5787 \mathrm{MHz}, \mathrm{f}_{\mathrm{TM} 31}=5245$ $\mathrm{MHz}, \mathrm{f}_{\mathrm{TM} 13}=6011 \mathrm{MHz}, \mathrm{f}_{\mathrm{TM} 32}=6218 \mathrm{MHz}, \mathrm{f}_{\mathrm{TM} 23}=6638$ $\mathrm{MHz}, \mathrm{f}_{\mathrm{TM} 33}=7568 \mathrm{MHz}$. The RMSA is simulated using IE3D software for two different feed point locations as shown in Fig. 4(a) and their resonance curve plots are shown in Fig. 4(b). When the feed is placed at location 'A', the peaks due to $\mathrm{TM}_{01}(1984 \mathrm{MHz}), \mathrm{TM}_{20}(2701 \mathrm{MHz})$ and $\mathrm{TM}_{21}(3520 \mathrm{MHz})$, modes are present. Also in higher frequency region, a peak due to weakly excited $\mathrm{TM}_{12}(4288 \mathrm{MHz})$ mode is present. When the feed is placed at point ' $\mathrm{B}$ ', additional resonant peaks due to $\mathrm{TM}_{10}(1564 \mathrm{MHz}), \mathrm{TM}_{11}(2572 \mathrm{MHz})$, weakly excited $\mathrm{TM}_{02}(3376 \mathrm{MHz})$ modes are present. These resonance frequencies are closer to their calculated values. In the reported configuration, the feed point is placed along the line joining center of patch and center of the length and therefore, $\mathrm{TM}_{10}$ and $\mathrm{TM}_{11}$ modes will not get excited. Further with feed point at point ' $A$ ', the outer U-slot of dimension $1_{s 1}$ and $l_{b 1}$ is cut inside the patch. The slot dimension is increased in steps and the resonance curve plots for this variation are shown in Fig. 4(c) and 5(a, b). Initially the decrease in various resonant mode frequencies with an increase in horizontal slot length $\left(l_{b 1}\right)$ is negligible.

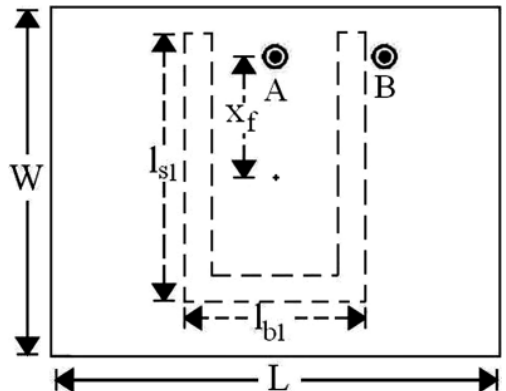

(a)

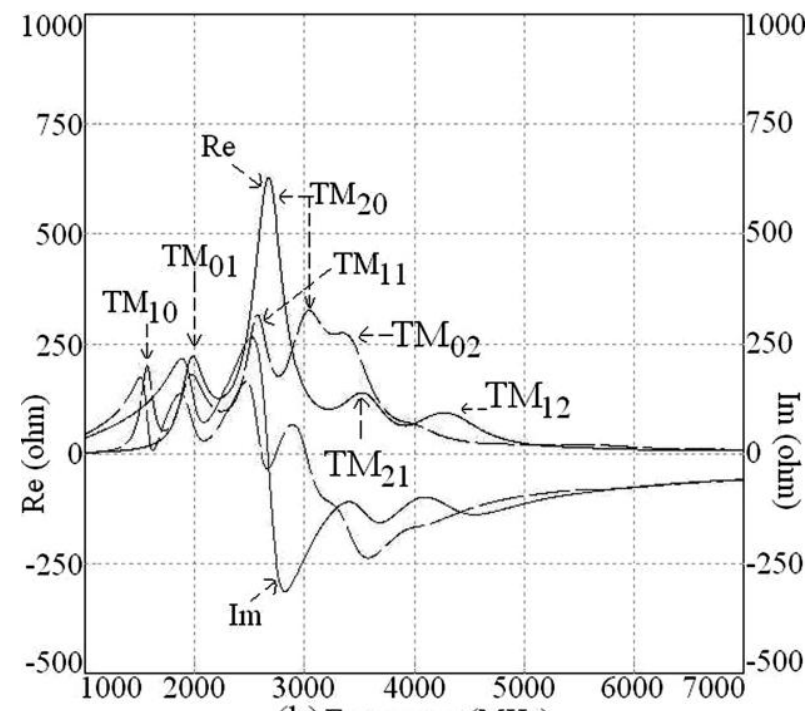

(b) Frequency $(\mathrm{MHz})$

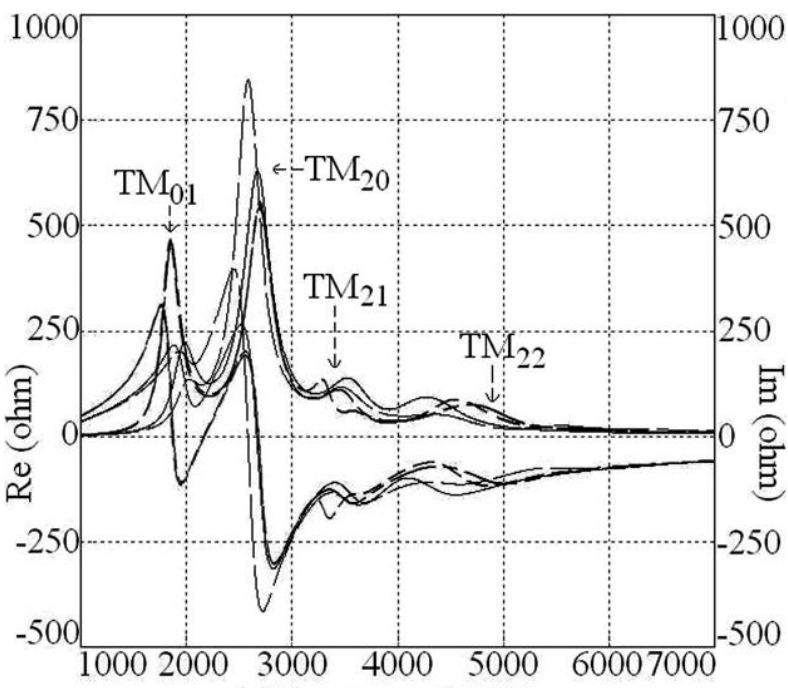

(c)Frequency $(\mathrm{MHz})$

Fig. 4 (a) U-slot cut RMSA, its resonance curve plots for (b) (-) feed point at ' $A$ ', (- $(-)$ feed point at ' $B$ ' and (c) $(\square) l_{s 1}=0 \mathrm{~cm}, l_{b 1}=0 \mathrm{~cm},(-\longrightarrow) l_{s 1}=0 \mathrm{~cm}, l_{b 1}=1.8 \mathrm{~cm}$, $(---) l_{\mathrm{s} 1}=1.0 \mathrm{~cm}, \mathrm{l}_{\mathrm{b} 1}=1.8 \mathrm{~cm},(---) \mathrm{l}_{\mathrm{s} 1}=1.4 \mathrm{~cm}, \mathrm{l}_{\mathrm{b} 1}=$ $1.8 \mathrm{~cm}$

Further with an increase in vertical U-slot length $\left(1_{s 1}\right)$ the various resonant mode $\left(\mathrm{TM}_{01}, \mathrm{TM}_{20}, \mathrm{TM}_{21}\right)$ frequencies reduces. At lower frequency band (i.e. $2100 \mathrm{MHz}$ ) the wide band response is realized when the vertical U-slot length optimizes the spacing between modified $\mathrm{TM}_{01}$ and $\mathrm{TM}_{20}$ mode frequencies. This is obtained for $1_{\mathrm{s} 1}=3.6 \mathrm{~cm}$ and feed point placed at $x_{\mathrm{f}}=-0.1 \mathrm{~cm}$, as shown in Fig. 5(c). 


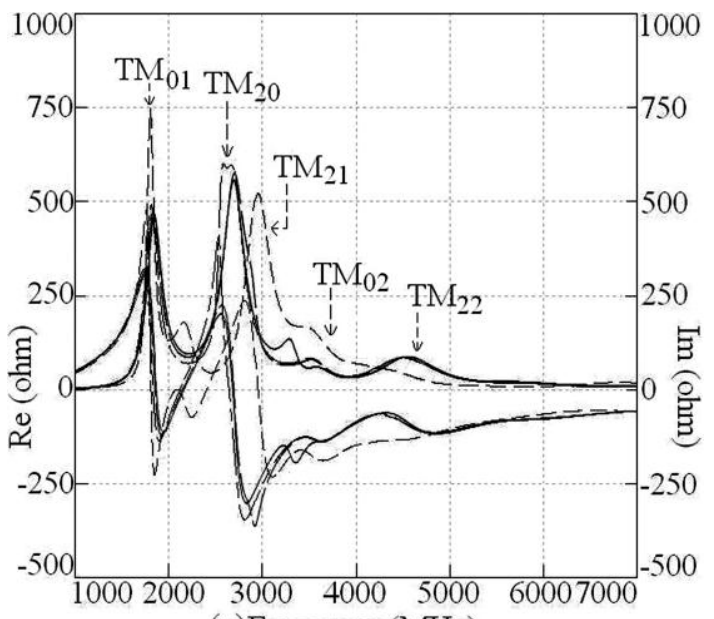

(a)Frequency $(\mathrm{MHz})$

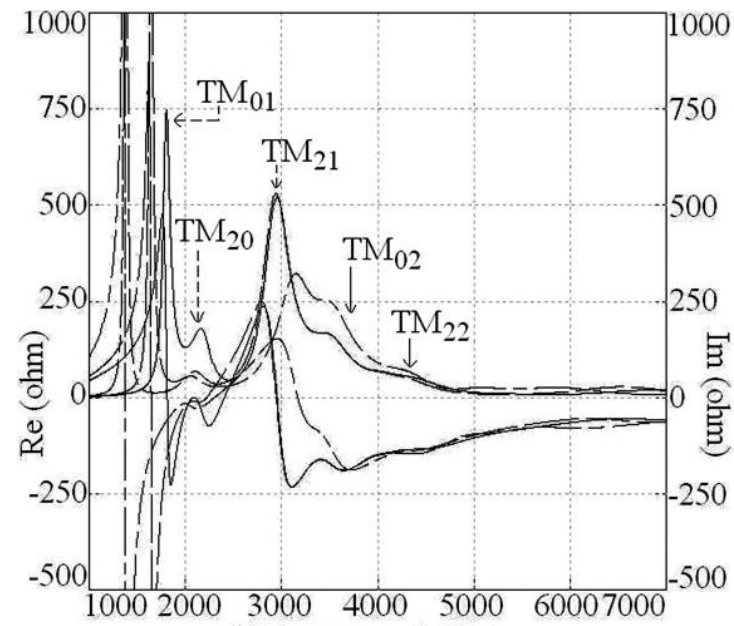

(b)Frequency $(\mathrm{MHz})$

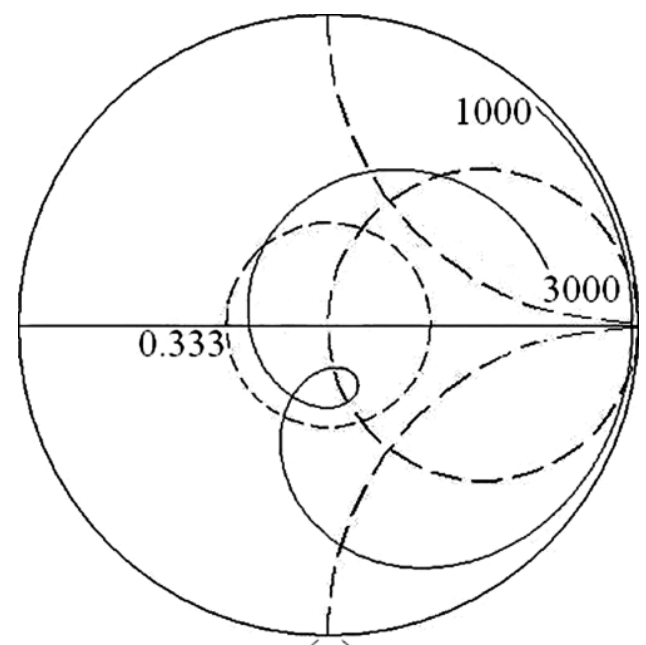

(c)

Fig. 5 Resonance curve plots for (a) $(-) l_{s 1}=1.4 \mathrm{~cm}, l_{b 1}=$ $1.8 \mathrm{~cm},(-\longrightarrow) l_{\mathrm{s} 1}=1.8 \mathrm{~cm}, \mathrm{l}_{\mathrm{b} 1}=1.8 \mathrm{~cm},(---) l_{\mathrm{s} 1}=2.2$ $\mathrm{cm}, \mathrm{l}_{\mathrm{b} 1}=1.8 \mathrm{~cm},(---) \mathrm{l}_{\mathrm{s} 1}=2.6 \mathrm{~cm}, \mathrm{l}_{\mathrm{b} 1}=1.8 \mathrm{~cm},(\mathrm{~b})(-)$ $l_{s 1}=1.4 \mathrm{~cm}, l_{b 1}=2.6 \mathrm{~cm},(--) l_{s 1}=1.8 \mathrm{~cm}, l_{b 1}=3.0 \mathrm{~cm}$, $(---) l_{\mathrm{s} 1}=3.6 \mathrm{~cm}, \mathrm{l}_{\mathrm{b} 1}=1.8 \mathrm{~cm}$ and $(\mathrm{c})$ simulated input impedance plot for $l_{\mathrm{s} 1}=\mathbf{3 . 6} \mathrm{cm}$

The realized simulated $\mathrm{BW}$ is $462 \mathrm{MHz}(21.25 \%)$. The surface current distributions at modified $\mathrm{TM}_{01}$ and $\mathrm{TM}_{20}$ modes for this slot length are shown in Fig. 6(a,b). The slot has modified current distributions at two resonant modes and they are aligned along vertical direction inside the patch. This gives broadside radiation pattern over the wide band response without any variations in the directions of principle planes. The slot length also reduces higher order mode resonance frequencies like $\mathrm{TM}_{02}, \mathrm{TM}_{22}$ and $\mathrm{TM}_{31}$ etc. Further inside first U-slot, second U-slot of dimension $1_{\mathrm{s} 2}$ and $\mathrm{l}_{\mathrm{b} 2}$ is cut as shown in Fig. 6(c), and resonance curve plots for varying lengths are shown in Fig. 7(a). The second U-slot primarily modifies and optimizes the impedance at higher order $\mathrm{TM}_{02}, \mathrm{TM}_{22}$ and $\mathrm{TM}_{31}$ mode resonance frequencies. The surface current distributions at these higher order modes/peaks for $1_{\mathrm{s} 2}=0.6$ $\mathrm{cm}$ is shown in Fig. 7(b, c). These surface current distributions are due to the close proximity of $\mathrm{TM}_{02}, \mathrm{TM}_{22}$ and $\mathrm{TM}_{31}$ resonant modes.

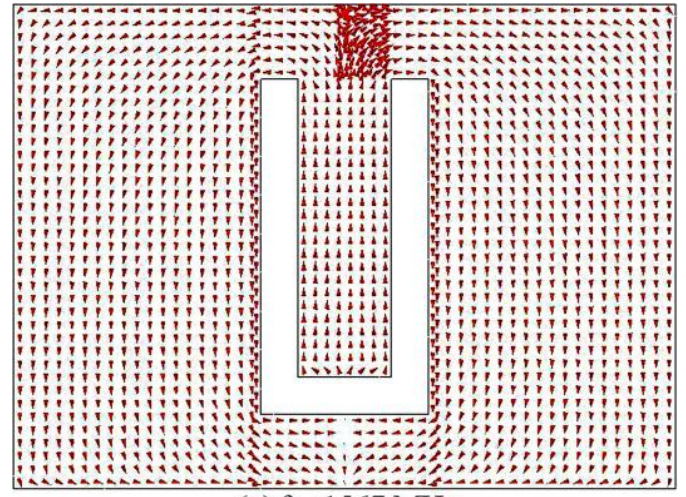

(a) $\mathrm{f}=1567 \mathrm{MHz}$

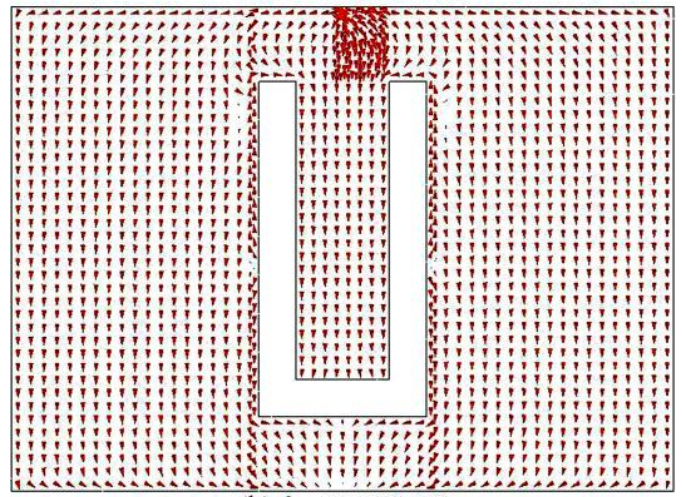

(b) $\mathrm{f}=2075 \mathrm{MHz}$

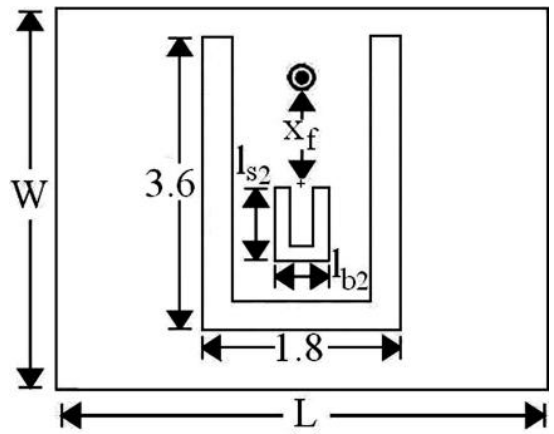

(c)

Fig. 6 Surface current distribution at modified (a) $\mathrm{TM}_{01}$ and (b) $\mathrm{TM}_{20}$ modes for $U$-slot cut RMSA for $\mathrm{I}_{\mathrm{s} 1}=\mathbf{3 . 6} \mathrm{cm}$, $I_{b 1}=1.8 \mathrm{~cm}$, (c) double U-slot cut RMSA 


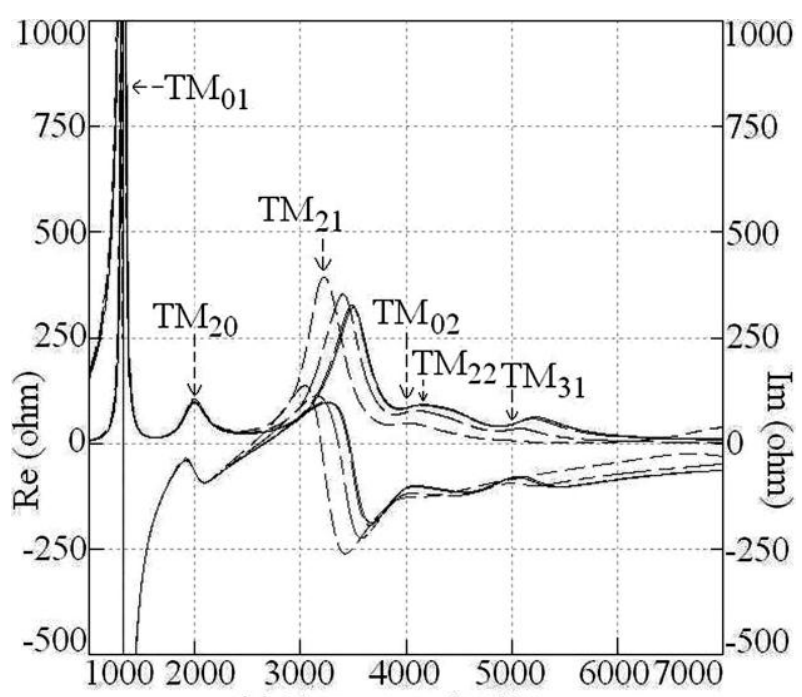

(a) Frequency $(\mathrm{MHz})$

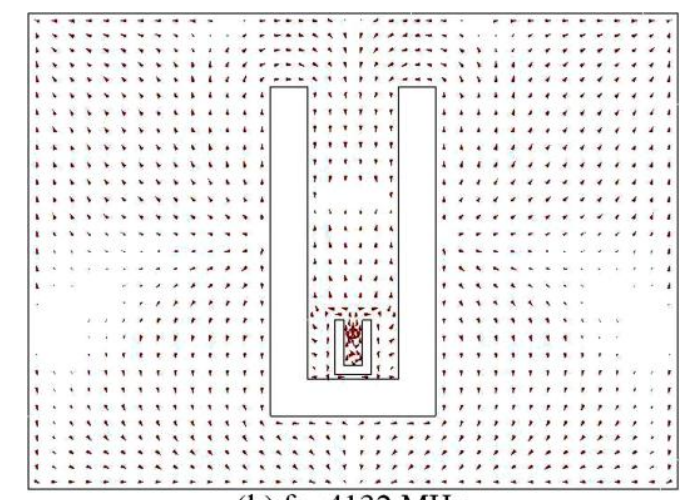

(b) $\mathrm{f}=4132 \mathrm{MHz}$

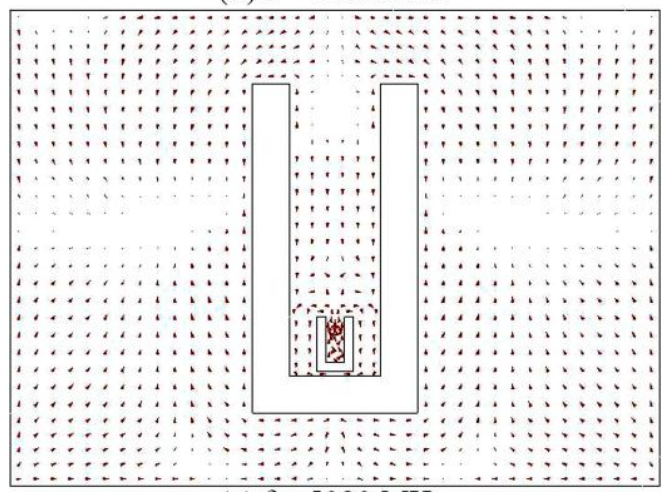

(c) $\mathrm{f}=5080 \mathrm{MHz}$

Fig. 7 (a) Resonance curve plots for $l_{s 1}=3.6 \mathrm{~cm}$ and $(-)$ $\mathrm{l}_{\mathrm{s} 2}=0.2 \mathrm{~cm},(-\square) \mathrm{l}_{\mathrm{s} 2}=0.4 \mathrm{~cm},(--\square) \mathrm{l}_{\mathrm{s} 2}=0.6 \mathrm{~cm},(--$ $-\mathbf{l}_{\mathrm{s} 2}=0.8 \mathrm{~cm}$ and $(\mathrm{b}, \mathrm{c})$ surface current distributions at higher order modes/peaks for $\mathrm{I}_{\mathrm{s} 2}=\mathbf{0 . 6} \mathrm{cm}$ for double $\mathrm{U}$ slot cut RMSA

The optimum response is obtained for $1_{\mathrm{s} 2}=1.0 \mathrm{~cm}$ and $\mathrm{x}_{\mathrm{f}}=$ $0.9 \mathrm{~cm}$. Since the surface currents at higher frequency band (i.e. around $5100 \mathrm{MHz}$ ) shows variations in horizontal as well as vertical directions, the radiation pattern at higher frequency band shows higher cross polar levels.

\section{CONCLUSIONS}

The analysis of dual and wide band response of double U-slot cut RMSA is presented. The first U-slot reduces the resonance frequencies of $\mathrm{TM}_{01}$ and $\mathrm{TM}_{20}$ modes and optimizes the impedance at them to realize wide band response at lower frequency i.e. $2100 \mathrm{MHz}$ band. Since the outer U-slot modifies the surface current distributions at $\mathrm{TM}_{01}$ and $\mathrm{TM}_{20}$ modes, the radiation pattern over the operating band remains in broadside direction. The second U-slot which is cut inside the first U-slot, further optimizes the resonance frequencies and impedance at $\mathrm{TM}_{02}, \mathrm{TM}_{22}$ and $\mathrm{TM}_{31}$ modes and yields dual frequency response around $5100 \mathrm{MHz}$. The proposed analysis will help in understanding the functioning of multiple slot cut MSAs.

\section{REFERENCES}

[1] Wong, K. L. 2002. Compact and Broadband Microstrip Antennas, John Wiley \& sons, Inc., New York, USA

[2] Ray, K. P., Nikhil, S., and Nair, A. 2009. Compact Tunable and Dual band Circular Microstrip Antenna for GSM and Bluetooth Applications, Interantional Journal of Microwave and Optical Technology, vol. 4, no. 4, (July 2009), $205-210$.

[3] Jhamb, K., Li, L., and Rambabu, K. 2011. Frequency adjustable microstrip annular ring patch antenna with multi-band characteristics, IET Microwave, Antennas and Propagation, vol. 5, no. 12, (December 2011), $1471-1478$.

[4] Lee, K. F., Yang, S. L. S., and Kishk, A. A. 2008. Dual and Multi-band U-slot patch Antennas, IEEE Antennas and wireless Propagation Letters, vol. 7, (2008), $645-647$.

[5] Lee, K. F., Luk, K. M., Mak, K. M., and Yang, S. L. S. 2011. On the use of U-slots in the design of Dual and Triple band Patch Antennas, IEEE Antennas and Propagation Magazine, AP - 53, no. 3, (2011), 60 74.

[6] Vedaprabhu, B., and Vinoy, K. J. 2010. An Integrated Wideband Multifunctional Antenna using a Microstrip patch with two U-slots, Progress In Electromagnetic Research B, vol. 22, (2010), 221 235.

[7] Li, R., Pan, B., Laskar, J., and Tentzeris, M. M. 2008. A novel low-profile broadband dual-frequency planar antenna for wireless handsets, IEEE Trans. Antennas Propagation, vol. 56, 2008, 1155 - 1162.

[8] Hwang, K. C. 2009. Dual-wideband monopole antenna using a modified half-Sierpinski fractal gasket, Electronics Letters, vol. 45, 2009, 487 - 489.

[9] Mahatthanajatuphat, C., Saleekaw, S., Akkaraekthalin, P., and Krairiksh, M. 2009. A rhombic patch monopole antenna with modified Minkowski fractal geometry for UMTS, WLAN, and mobile WiMAX application, Progress In Electromagnetics Research, vol. 89, 2009, 57 - 74

[10] Mahatthanajatuphat, C., Akkaraekthalin, P., Saleekaw, S., and Krairiksh, M. 2009. A bidirectional multiband antenna with modified fractal slot fed by CPW, Progress In Electromagnetics Research, vol. 95, 2009, $59-72$.

[11] Deshmukh, A. A., Ray, K. P., and Kadam, A. 2013. Analysis of slot cut Broadband and Dual band Rectangular Microstrip Antennas, IETE Journal of Research, vol. 59, no. 3, (May - June 2013), 193 200.

[12] IE3D 12.1, 2004. Zeland Software, Freemont, USA 